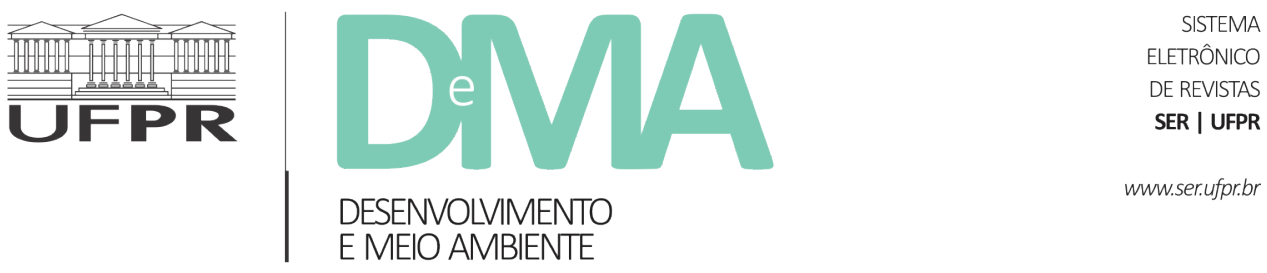

\title{
Da floresta ao litoral: instrumentos de cogestão e o legado institucional das Reservas Extrativistas
}

\section{From the forest to the coast: co-management instruments and the institutional legacy of Extractive Reserves}

\author{
Deborah Santos PRADO ${ }^{1 *}$, Cristiana Simão SEIXAS ${ }^{1}$ \\ ${ }^{1}$ Núcleo de Estudos e Pesquisas Ambientais (NEPAM), Universidade Estadual de Campinas (Unicamp), Campinas, SP, Brasil. \\ *E-mail de contato: deborah.stprado@yahoo.com.br
}

Artigo recebido em 6 de abril de 2018, versão final aceita em 16 de agosto de 2018.

\begin{abstract}
RESUMO: Diversos autores têm trazido contribuições elucidativas sobre a evolução das reservas extrativistas (Resex), desde sua concepção original, até sua institucionalização como política ambiental. Parte dessa literatura aponta transformações nos arranjos de gestão desses territórios, quando passam a ser formalizados e reconhecidos pelo Estado. Este artigo apresenta um mapeamento dos instrumentos de cogestão das reservas extrativistas marinhas e uma análise da evolução de seus arranjos formais, a partir de dados secundários e análise documental da legislação pertinente desde o primeiro decreto de criação das Resex. Além disso, foram realizadas entrevistas semiestruturadas com gestores do ICMBio de 21 Resex costeiras e marinhas, com o objetivo de identificar todos os instrumentos de cogestão utilizados em cada Resex, bem como seu estágio de implementação e a percepção dos gestores sobre esses instrumentos. Consideramos como instrumentos de cogestão os arranjos formais que se concretizam em ações de gestão compartilhada no território dessas Unidades de Conservação (UCs) ou que atuam como arenas para a tomada de decisão. Os resultados mostram que o legado do movimento seringueiro também se apresenta nos arranjos formais estabelecidos no decorrer do tempo. Os instrumentos de cogestão das Resex marinhas se dividiram em instrumentos de reconhecimento territorial e de beneficiários, instrumentos de ordenamento sobre os usos do território, instrumentos que se configuram como arenas de discussão e deliberação, além de políticas públicas institucionalizadas para as Resex. Esse arcabouço institucional foi se tornando cada vez mais robusto com o tempo, ainda que necessite ser aprimorado. Parte dos desafios incluem a diminuição dos trâmites processuais para o reconhecimento formal dos instrumentos e a lógica tecnocrática do Estado que muitas vezes exerce tutela e não promove a emancipação social dos povos do mar.
\end{abstract}

Palavras-chave: arranjos institucionais; gestão participativa; legislação ambiental. 
ABSTRACT: Several authors have made elucidative contributions on the evolution of extractive reserves (Resex), from their original conception to their institutionalization as an environmental policy. Part of this literature points out transformations on the institutional arrangements, when they are formalized and recognized by the State. This article presents the co-management instruments of Brazilian Marine Extractive Reserves and an analysis of their formal arrangements evolution, based on secondary data and an assessment of pertinent legislation since the first Resex decree. In addition, semi-structured interviews were conducted with 21 managers of Coastal and Marine Resex. The interviews aimed to identify all co-management instruments used in each Resex, their stage of implementation as well as the managers' perception on these instruments. We consider co-management instruments as formal arrangements that require participatory procedures or that act as arenas for decision-making. The results show that the legacy of the rubber tappers social movement in 80 's, which created an inclusive model of protected area, is presented in the formal arrangements established over time. The instruments for co-management are divided into instruments of territorial recognition and beneficiaries, instruments for land use planning, arenas for discussion and deliberation, as well as public policies for Resex. This institutional framework has become increasingly robust over time, although it still needs to be improved. Part of the challenges include a reduction on bureaucratic procedures for the formal recognition of these instruments and the technocratic logic of the State that is often exercising tutelage rather than social emancipation of traditional people.

Keywords: institutional arrangements; participatory management; environmental legislation.

\section{Introdução}

Diversos autores têm trazido contribuições elucidativas sobre a evolução das Reservas Extrativistas (Resex), desde sua concepção original até sua institucionalização como política ambiental (Allegretti, 1994; 2008; Murrieta \& Rueda, 1995; Porto Gonçalves, 1999; Cunha, 2001; Almeida, 2004; Vianna \& Sales, 2008). Parte dessa literatura aponta transformações na principal proposta das Resex e, consequentemente, nos arranjos de gestão desses territórios.

Desde sua institucionalização, diversos grupos sociais têm visualizado as Resex como um arranjo institucional formal para proteção de seus territórios tradicionalmente ocupados. No ecossistema costeiro-marinho, esses conflitos envolvem diversos setores econômicos, como o setor de petróleo e gás, a pesca industrial, o turismo, e outros grandes empreendimentos que se somam à especulação imobiliária e aos processos de urbanização desordenada do litoral. Nessa complexidade socioeconômica, a pesca artesanal tem grande relevância, não só pela expressividade na produção pesqueira nacional, como também na reprodução social e simbólica de várias comunidades ao longo da costa, que ainda resistem às ameaças quanto ao uso e acesso aos recursos naturais.

A expansão do conceito Resex para a zona costeira pautava-se não somente em tentar evitar a especulação imobiliária do litoral, como também em dividir o lastro institucional das Resex, a fim de não concentrar suas ações somente em áreas amazônicas (Chamy, 2005). Desde 1992, quando a primeira reserva extrativista marinha foi criada, a demanda pela criação de novas Resex na zona costeira aumentou significativamente, sendo que, até julho de 2018, 28 Resex federais foram criadas ${ }^{1}$,

\footnotetext{
${ }^{1}$ Além das 28 Resex sob tutela do Instituto Chico Mendes de Conservação da Biodiversidade (ICMBio), existem outras três Resex estaduais ao longo da costa: Resex Taquari e Ilha do Tumba em São Paulo e Resex Marinha Itaipu no Rio de Janeiro. Outras Resex estão em processo de criação e um número maior de pedidos de criação tramita no ICMBio e em órgãos estaduais competentes.
} 
com diferentes estágios de implementação dos instrumentos de cogestão.

A cogestão tem sido definida como uma série de arranjos colaborativos e compartilhados de tomada de decisão entre usuários, governo e outros atores envolvidos no processo (como universidades, organizações não-governamentais, setor privado etc.) (Jentoft, 2003). Trata-se de uma perspectiva de gestão que pressupõe o compartilhamento de poder e responsabilidades (Carlsson \& Berkes, 2005), a cooperação e o uso de uma pluralidade de formas de conhecimento (Armitage et al. 2007) na gestão de um território. Apesar das variáveis contextuais e políticas, também é fundamental compreender o desenho institucional (Faria \& Ribeiro, 2011) das Resex e como sua evolução vem oferecendo os parâmetros - regras e procedimentos - para seu desempenho enquanto modelo de cogestão. Este artigo tem o objetivo de apresentar a evolução do desenho institucional das Resex desde 1990 e um mapeamento dos instrumentos de cogestão existentes, com foco nas Resex Costeiras e Marinhas do Brasil.

Consideraremos como instrumentos de cogestão os arranjos formais que se concretizam em ações de gestão no território dessas Unidades de Conservação (UCs), ou que atuam como ferramentas e espaços para a tomada de decisão, sendo em geral previstos em normas legais e administrativas. Após apresentação dos métodos, a primeira seção do artigo mostra o histórico e a evolução dos primeiros instrumentos de cogestão das Resex, seguido do arcabouço de arranjos disponíveis a partir do SNUC e de um levantamento atual dos instrumentos disponíveis, que já têm sido utilizados ou que ainda estão em fase de elaboração e implementação nas Resex da zona costeira.

\section{Métodos de pesquisa}

Foram realizadas entrevistas semiestruturadas com gestores do ICMBio que estavam no exercício da chefia ${ }^{2}$ de 21 Resex Costeiras e Marinhas entre setembro e novembro de 2016, com o objetivo de identificar todos os instrumentos de cogestão utilizados em cada UC, bem como seu estágio de implementação e a percepção dos gestores sobre esses instrumentos ${ }^{3}$. No total de 25 Resex federais existentes em 2016, não foi possível realizar a entrevista na Resex Delta do Parnaíba por dificuldades de agenda da gestora responsável, e não foram incluídas na amostra três Resex decretadas em 2014, no estado do Pará: Resex Mocapajuba, Cuinarana e Mestre Lucindo, que ainda estavam em fase de implementação. Em abril de 2018, três novas Resex marinhas foram criadas no Maranhão (Arapiranga-Tromaí, Baía do Tubarão e Itapetininga), totalizando 28 unidades (Figura 1).

A maioria das entrevistas foi feita por telefone, tendo em vista a amplitude geográfica que envolvia todas as Resex. Em três casos específicos, as entrevistas foram realizadas pessoalmente. As entrevistas realizadas remotamente cumpriram os objetivos propostos e não apresentaram limitações significativas, embora o processo de implementação

\footnotetext{
${ }^{2}$ Em apenas duas Resex que estavam temporariamente sem gestor, foram entrevistados os gestores anteriores (Resex Tracuateua e Resex Maracanã-PA).

${ }^{3}$ As Reservas Extrativistas Marinhas analisadas neste artigo são: Pirajubaé (SC); Mandira (SP); Arraial do Cabo (RJ); Cassurubá; Corumbau; Canavieiras; Baia de Iguape (BA); Lagoa do Jequiá (AL); Acaú-Goiana (PB/PE); Prainha do Canto Verde; Batoque (CE); Cururupu (MA); Chocoaré- Mato Grosso; Maracanã; Mãe Grande de Curuçá; São João da Ponta; Tracuateua; Gurupi-Piriá; Araí Peroba; Caeté-Taperaçu e Soure (PA).
} 


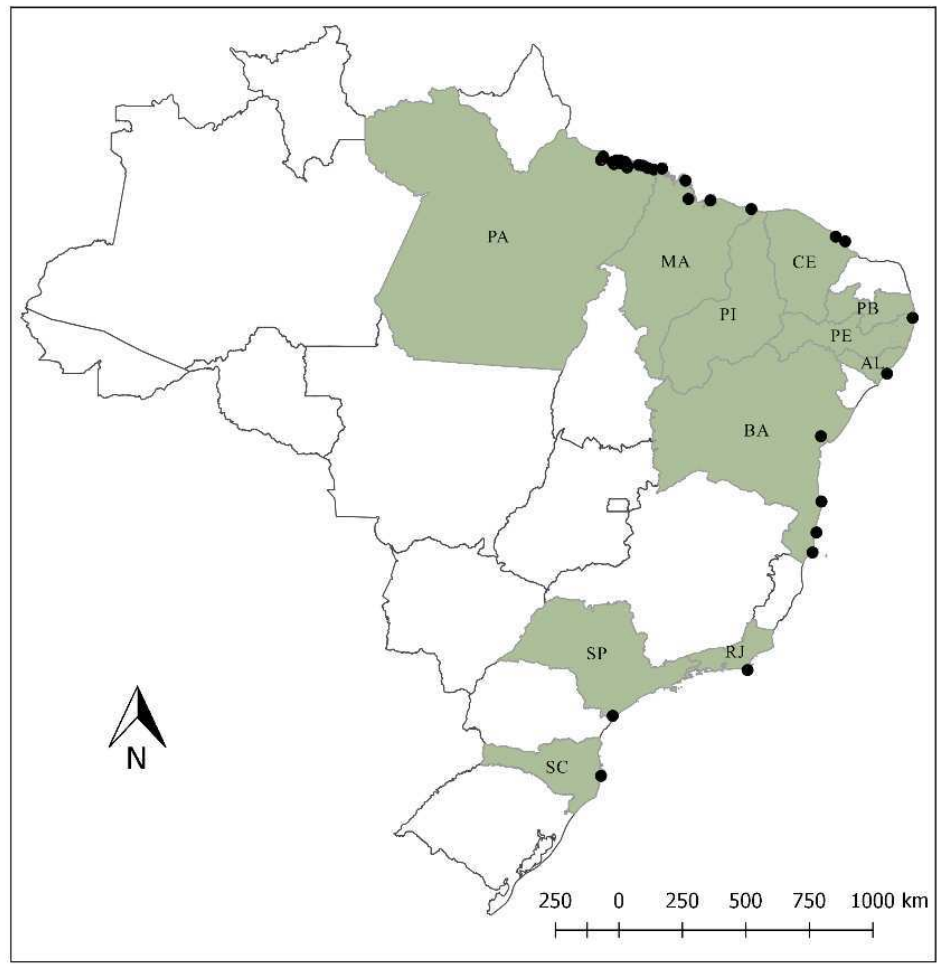

\section{Distribuição Geográfica \\ RESERVAS \\ EXTRATIVISTAS \\ COSTEIRAS E MARINHAS \\ DO BRASIL}

\section{Legenda \\ - RESEX Costeiras e Marinhas (2018) \\ estados \\ Número de RESEX por estado: PA (12): MA (4); PI/MA (1); CE (2); PB/PE (1); AL (1); $\mathrm{BA}(4) ; \mathrm{RJ}$ (1); $\mathrm{SP}$ (1); $\mathrm{SC}$ (1)

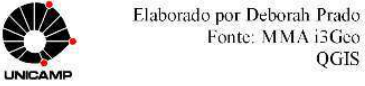

FIGURA 1 - Distribuição das Reservas Extrativistas costeiras e marinhas pelos estados brasileiros até julho de 2018.

de alguns instrumentos de cogestão realizados há mais tempo nem sempre pudesse ser explanado por todos os gestores, muitos dos quais haviam sido nomeados recentemente como chefes das Resex.

Além das 21 entrevistas, a análise sobre o histórico e evolução dos instrumentos de cogestão também se baseou em dados secundários e análise documental da legislação pertinente a partir do primeiro decreto de criação das Resex. As normas analisadas são apresentadas na Tabela 1.

\section{Resultados e discussão}

\subsection{Histórico dos primeiros instrumentos de cogestão}

A partir da institucionalização das Resex em 1990 (Decreto Federal $n^{\circ}$ 98.897), coube ao IBAMA regulamentar essa nova categoria de área protegida, alçando o poder público à condição de sujeito ativo na responsabilidade pelas Resex (Gomes \& Felippe, 1994). O IBAMA assumiu a responsabilidade de "supervisionar" as áreas extrativistas e, dois anos após a sua criação como figura jurídica na legislação ambiental brasileira, as Resex passaram a ser geridas especificamente pelo Centro Nacional de 
TABELA 1 - Legislação Ambiental analisada no artigo, referente aos instrumentos de cogestão aplicáveis às Reservas Extrativistas Costeiras e Marinhas do Brasil. Entre as normas analisadas foram consideradas também algumas já revogadas (*), no intuito de compreender o processo de evolução dos instrumentos normativos.

\begin{tabular}{ll}
\hline Legislação & Objetivos \\
\hline Decreto no 98.897 de $1990^{\text {Portaria do IBAMA no } 51 \text { de } 1994 *}$ Dobre as reservas extrativistas e dá outras providências \\
\hline Portaria do IBAMA n 118 de $1994 *$ & $\begin{array}{l}\text { Aprova o Roteiro para Criação e Legalização das Reservas Extrativistas } \\
\text { Aprova as Normas Administrativas para Criação, Regularização e Consolidação das } \\
\text { Reservas Extrativistas }\end{array}$ \\
\hline
\end{tabular}

Estabelece e uniformiza o procedimento administrativo acerca do processo de Instrução Normativa do IBAMA nº 02 de 1998 * Identificação, Criação e Regularização Fundiária de Unidades de Conservação e revoga a Instrução Normativa IBAMA nº 51 de 1994

Portaria do IBAMA n ${ }^{\circ} 76$ de 1999

Lei ${ }^{\circ} 9.985$ de 2000

Decreto n ${ }^{\circ} 4.340$ de 2002

Portaria do IBAMA n ${ }^{\circ} 29$ de 2002

Decreto $\mathrm{n}^{\circ} 5.758$ de 2006

Instrução Normativa do ICMBio nº 01 de 2007

Instrução Normativa do ICMBio n ${ }^{\circ} 02$ de 2007 *

Instrução Normativa do ICMBio n ${ }^{\circ} 03$ de 2007

Decreto $\mathrm{n}^{\mathrm{o}} 7.572$ de 2011

Instrução Normativa do ICMBio no 29 de 2012

Instrução Normativa do ICMBio n ${ }^{\circ} 37$ de 2013

Instrução Normativa do ICMBio nº 09 de 2014

Instrução Normativa $\mathrm{n}^{\circ} 7$ de 2017
Revoga a Instrução Normativa n ${ }^{\circ} 2$ de 1998, que estabelece e uniformiza procedimentos administrativos acerca do processo de identificação, criação e regularização fundiária de UCs

Institui o Sistema Nacional de Unidades de Conservação da Natureza e dá outras providências

Regulamenta artigos da Lei $N^{\circ}$ 9.985, de 2000, que dispõe sobre o SNUC, e dá outras providências

Estabelece critérios e procedimentos para a regulamentação de Acordos de Pesca em comunidades pesqueiras

Institui o Plano Estratégico Nacional de Áreas Protegidas - PNAP, seus princípios, diretrizes, objetivos e estratégias, e dá outras providências.

Disciplina as diretrizes, normas e procedimentos para a elaboração de Plano de Manejo Participativo de UC Federal das categorias Resex e RDS.

Disciplina as diretrizes, normas e procedimentos para formação e funcionamento do Conselho Deliberativo de Resex e de RDS.

Disciplina as diretrizes, normas e procedimentos para a criação de UC Federal das categorias reserva extrativista e Reserva de Desenvolvimento Sustentável.

Regulamenta dispositivos da Medida Provisória $n^{\circ}$ 535, de 2 de junho de 2011, que tratam do Programa de Apoio à Conservação Ambiental - Programa Bolsa Verde.

Disciplina as diretrizes, requisitos e procedimentos administrativos para a elaboração e aprovação de Acordo de Gestão em UCs de Uso Sustentável federal com populações tradicionais.

Disciplina as diretrizes e procedimentos administrativos para elaboração e homologação do Perfil da Família Beneficiária em Resex, RDS e FLONAS.

Disciplina as diretrizes, normas e procedimentos para formação, implementação e modificação na composição de Conselhos Gestores de UCs Federais.

Estabelece diretrizes e procedimentos para elaboração e revisão de Planos de Manejo de unidades de conservação da natureza federais. 
Desenvolvimento Sustentado de Populações Tradicionais, o CNPT, órgão até então pertencente ao IBAMA, que assumiu ampla competência, não só relacionada à criação e à implementação das Resex, mas também ao desenvolvimento sustentável das populações tradicionais do país (Vianna \& Sales, 2008).

Os instrumentos de cogestão que constavam no primeiro decreto de criação das Resex se limitavam ao Contrato de Concessão de Direito Real de Uso (CCDRU), que garantia os processos de regularização fundiária das reservas, e ao Plano de Utilização (PU) da área. Em 1994, foi publicado um importante documento que orientou os processos de criação de diversas Resex que existem hoje: o Roteiro para Criação e Legalização das Reservas Extrativistas foi instituído pela Portaria do IBAMAn ${ }^{\circ} 51$ de 1994, e posteriormente complementada pela Portaria do IBAMA n ${ }^{\circ} 118$ de 1994. Esse roteiro tornou explícito o regime de cogestão das Resex e da marcante atuação do órgão ambiental na aprovação de seus instrumentos de cogestão ${ }^{4}$. Dentre os instrumentos cabíveis, já havia nesse documento a normatização detalhada a respeito do CCDRU e dos Planos de Utilização, que apenas estavam mencionados no decreto de 1990. Houve também a normatização de um novo instrumento, o então chamado Plano de Desenvolvimento das reservas.

O Roteiro de Criação e Legalização das Reservas Extrativistas consolidou os primeiros instrumentos de cogestão dessas UCs, ainda que com um forte viés amazônico. Esses instrumentos passaram a dar as diretrizes ao funcionamento de todas as reservas, com atenção especial aos Planos de Utilização.
Os Planos de Utilização são considerados por alguns autores como instrumentos inovadores e funcionais em sua proposta inicial (Almeida \& Pantoja, 2004; Vianna \& Sales, 2008). Dentre essas inovações estava a simplicidade e praticidade de utilização do instrumento, "um documento prático, de fácil entendimento e aplicação, tendo um caráter preliminar em relação a outro instrumento de gestão, o Plano de Desenvolvimento da reserva" (Vianna \& Sales, 2008, p. 12). Em sua concepção inicial, os Planos de Utilização deveriam registrar as formas costumeiras já implementadas no manejo de recursos naturais (Almeida \& Pantoja, 2004), e deveriam ser estabelecidos pelos moradores, desde a sua elaboração até a aplicação e a fiscalização, cabendo ao órgão gestor os encargos de assessoria, aprovação formal, por meio da averiguação do cumprimento da legislação vigente, e cofiscalização (Vianna \& Sales, 2008).

Com a necessidade dos Planos de Desenvolvimento, cinco anos após o decreto de institucionalização das Resex, o Estado passa a requerer informações mais detalhadas e um planejamento de diversos aspectos técnicos do funcionamento das reservas, mais próximos da proposta do que devem ser hoje os Planos de Manejo. Em Portaria complementar (Portaria do IBAMA n ${ }^{\circ} 118$ de 1994), os Planos de Desenvolvimento passaram a ser considerados "o principal instrumento de gestão da reserva" (art. $\left.10^{\circ}\right)$. Ainda assim, Vianna \& Sales (2008) apontam que nenhum Plano de Desenvolvimento foi produzido de acordo com a Portaria, "havendo, entre a documentação disponível, raros registros sobre ações efetivas para sua elaboração" (p. 16).

${ }^{4}$ Até a publicação do roteiro, 9 Reservas Extrativistas já haviam sido criadas (Murrieta \& Rueda, 1995), incluindo a Primeira Resex Marinha, de Pirajubaé em 1992. 
Em 1998, as citadas Portarias do IBAMA de 1994, que continham as diretrizes para a criação e implementação das Resex, foram revogadas por meio da Instrução Normativa (IN) do IBAMA n 02 de 1998. Essa IN tinha por objetivo "uniformizar o procedimento administrativo acerca do processo de identificação, criação e regularização fundiária de todas as UCs do país". A IN, entretanto, não trouxe o mesmo detalhamento da norma anterior sobre os processos de criação, bem como de elaboração dos instrumentos de cogestão com atuação marcante das populações extrativistas.

Sobre os procedimentos prévios à criação das Resex, a IN no 02/98 deixou de contemplar alguns pontos considerados importantes, como a necessidade de existência de organizações sociais para gestão da Reserva, o detalhamento das práticas de manejo, a carta de anuência dos moradores e o processo de imissão de posse da área ao IBAMA para posterior concessão de direito real de uso às famílias locais. "Tal enquadramento reflete uma perda de força da categoria reserva extrativista entre os quadros do IBAMA, vista por muitos deles, desde o início dos anos noventa, como instrumento de resolução fundiária e não como unidade de conservação da natureza" (Vianna \& Sales 2008, p. 19).

No ano seguinte, $\mathrm{IN} \mathrm{n}^{\mathrm{o}}$ 02/98 também foi revogada ${ }^{5}$, pois, segundo Vianna \& Sales (2008), essa IN fazia com que os procedimentos para identificação e criação das UCs exigissem ampla consulta a variados arquivos públicos, registros e documentos legais e técnicos, sendo considerada uma dificuldade adicional para a viabilização de novas áreas protegidas.

O Decreto de criação das Resex e o conjunto de Portarias e Instruções Normativas mencionado anteriormente representaram o primeiro arcabouço formal de instrumentos de cogestão desenvolvidos anteriormente à Lei que instituiu o SNUC. Na primeira década de existência do modelo Resex, foi possível observar transformações de cunho formal e técnico, instituindo a presença do Estado no interior das Resex para chancela do uso e gestão dos recursos naturais, tanto florestais quanto marinhos.

\subsection{A gestão das Resex pós SNUC}

Com o estabelecimento do SNUC - Lei $n^{\circ}$ 9.985 (2000) regulamentada pelo Decreto $n^{\circ} 4.340$ (2002) - as Resex passaram a integrar o conjunto de UCs de Uso Sustentável. O arcabouço legal que passou a definir e normatizar os instrumentos de gestão de todas as UCs, incluindo as Resex, já vinha sendo discutido durante toda a década de 1990 , envolvendo diversas disputas entre socioambientalistas, preservacionistas e ruralistas ${ }^{6}$.

Alguns instrumentos anteriores ao SNUC caíram em desuso, como os Planos de Desenvolvimento das Resex, e novos arranjos formais foram apresentados a partir do SNUC, como é o caso dos Planos de Manejo e os Conselhos Deliberativos, além de outros programas e atos administrativos que serão discutidos a seguir e apresentados segundo seus principais objetivos.

\footnotetext{
${ }^{5}$ Revogada pela Portaria do IBAMA no 76 de 1999.

6 "Ao longo de extensos oito anos de debates, preservacionistas, conservacionistas, socioambientalistas e ruralistas travaram uma verdadeira batalha que mobilizou a imprensa, ONGs, além de fortíssimos lobbys no Congresso na defesa de suas posições sobre a forma e os critérios de proteção da natureza. Entre os pontos mais polêmicos destacavam-se a questão das populações tradicionais, a participação popular no processo de criação e gestão de UCs e as indenizações para desapropriações” (Medeiros, 2006, p. 57).
} 
A partir dos dados que emergiram nas entrevistas com gestores das Resex Costeiras e Marinhas do Brasil, definimos as seguintes tipologias de instrumentos de cogestão: a) Instrumentos de reconhecimento territorial e de beneficiários do território: Contrato de Concessão de Direito Real de Uso (CCDRU) e Perfil da Família Beneficiária;

b) Instrumentos de ordenamento sobre os usos do território: Plano de Utilização, Acordo de Gestão, Plano de Manejo e Acordo de Pesca; c) Instrumentos que se configuram como arenas de discussão e deliberação: Conselhos Deliberativos, Comitês de Gestão/Comunitários e finalmente d) Programas e Políticas Públicas institucionalizadas em Resex: Programa Nacional de Reforma Agrária e Programa Bolsa Verde. As informações mais sistematizadas sobre os instrumentos de cogestão mencionados também constam na Tabela 2.

\subsubsection{Instrumentos de reconhecimento territorial e de beneficiários do território}

\section{Contrato Concessão de Direito Real de Uso (CCDRU)}

O processo de regularização fundiária e consequente emissão do CCDRU não havia ocorrido em 7 Resex Costeiras e Marinhas até novembro de 2016. Os ritos administrativos envolvem primeiramente a concessão entre órgãos públicos: da Secretaria de Patrimônio da União (SPU) ao Ministério do Meio Ambiente (MMA) e deste para o ICMBio. O ICMBio concede o direito de uso a uma associação comunitária, que passa a ser a concessionária da área. A concessionária tem uma série de cláusulas a serem cumpridas no contrato, com riscos de fiscalização, autuação e até rescisão da concessão, prevista inicialmente por um período de 20 anos.

Para que haja a concessão de uso para a comunidade extrativista, as terras que se encontram dentro dos limites das Resex devem ser regularizadas por meio de procedimentos administrativos e/ou judiciais promovidos pelo ICMBio. Como dificilmente as áreas requisitadas para a implantação das Resex estão inseridas totalmente em terras públicas ou devolutas, a regularização normalmente envolve processos de desapropriação, usualmente lentos e que demandam recursos muitas vezes não previstos no orçamento $^{7}$ (Chamy, 2005).

Outra questão importante a ser levantada quanto ao CCDRU é a necessidade da constituição de uma Associação para figurar como concessionária do direito real, representando os interesses das comunidades locais (Milano, 2011). Embora o papel das associações tenha passado a ser fundamental na consolidação das Resex, inclusive por orientações normativas, muitos gestores relataram conflitos entre associações locais e também entre as diversas condicionantes e limitações administrativas que são impostas pelo CCDRU às organizações de base comunitária.

\section{Perfil da Família Beneficiária}

A partir da IN do ICMBio no 35 de 2013, passou a ser necessário descrever os critérios ou as características das famílias beneficiárias, detentoras

\footnotetext{
${ }^{7}$ Uma forma de reduzir esse impasse foi demarcar muitas Resex apenas em áreas de manguezais e lâmina d'água, por serem configuradas como Terreno de Marinha. Isso foi relatado, por exemplo, por diversos gestores do Estado do Pará, sobre o processo de criação dessas unidades, como forma de sanar os impasses de desapropriação, como também de negociações com o governo do estado.
} 
do direito ao território compreendido pelas Resex e outras UCs de Uso Sustentável. Diversos procedimentos administrativos são previstos na $\mathrm{IN} \mathrm{n}^{\circ} 35 \mathrm{de}$ 2013, tais como a criação de um Grupo de Acompanhamento para a atividade de definição do Perfil, discussões realizadas nas comunidades, avaliação do processo e manifestação técnica feita pela Coordenação Geral de Populações Tradicionais, assim como a aprovação e a homologação do mesmo via resolução do Conselho Deliberativo. Os perfis das famílias são publicados no Diário Oficial da União e são passíveis de recurso por desacordo de algum comunitário ou de revisão para sua atualização.

É importante mencionar que a norma para a elaboração do Perfil das Famílias Beneficiárias surgiu em função de uma demanda específica: de implementação do Programa Bolsa Verde (a ser descrito na sequência), e o estabelecimento de critérios bem definidos sobre os reais beneficiários da unidade. Antes dessa obrigatoriedade, a maioria das Resex possuía um cadastro ou um levantamento das famílias residentes estabelecidos pelo INCRA. A Relação de Beneficiários do INCRA era realizada para fins de inserção dos extrativistas no Programa Nacional de Reforma Agrária (PNRA). Por falta de critérios bem definidos, muitas famílias com perfil extrativista não foram contempladas com os créditos de instalação e fomento oferecidos pelo INCRA, em detrimento de outras famílias, que mesmo sem nenhuma relação com a pesca foram contempladas com a política pública. Esse processo acarretou um passivo de desconfiança e injustiça que ainda permeia a implementação de diversas Resex.

A partir das entrevistas e pela confirmação no Diário Oficial da União, 5 Resex não possuíam o
Perfil da Família Beneficiária publicado, ainda que relatem ter elaborado seu perfil e seu cadastro de famílias ${ }^{8}$. Além dos critérios reconhecidos no perfil, as Resex devem realizar um cadastro das famílias e mantê-lo atualizado. Alguns gestores também relataram problemas de entendimento por parte da Procuradoria Jurídica do ICMBio sobre os critérios estabelecidos pelo Conselho, com base na realidade local, para compor o perfil dos beneficiários.

\subsubsection{Instrumentos de ordenamento sobre os usos do território}

\section{Plano de Manejo}

Uma mudança marcante no contexto pós SNUC, quando comparada aos instrumentos previstos anteriormente, é a instituição do Plano de Manejo para Resex. Segundo o SNUC, o Plano de Manejo deve ser um documento técnico que estabelece o zoneamento e as normas que devem presidir o uso da área e o manejo dos recursos naturais, inclusive a implantação das estruturas físicas necessárias à gestão da unidade mediante seus objetivos. Ainda que no caso das Resex esteja assegurada pelo SNUC a ampla participação da população residente no processo de elaboração do plano, esse instrumento tem tido um caráter extremamente técnico e complexo, sendo inviabilizado por diversas questões logísticas, como a falta de recursos financeiros e humanos para coordenação e acompanhamento.

Embora também esteja estabelecido pelo SNUC que o Plano de Manejo de uma UC deve ser

${ }^{8}$ Em 3 casos, a informação não foi encontrada no diário oficial, e pelo fato de não ter sido confirmada no momento da entrevista, não podemos afirmar se o perfil já foi elaborado. A validação foi requisitada aos gestores, mas não foi concluída até o momento de escrita desse texto. 
elaborado no prazo de cinco anos a partir da data de sua criação, apenas três Resex da zona costeira (dentre 22 criadas há pelo menos cinco anos) possuíam seu Plano de Manejo homologado (Resex Mandira-SP, Caeté Taperaçu-PA e Cururupu-MA). Os gestores apresentaram razões de ordem institucional, que vão desde as prioridades do órgão (privilegiando durante alguns anos a elaboração de planos de UCs de proteção integral), até questões financeiras, de recursos humanos e rompimento de contratos com empresas de consultoria.

Em dezembro de 2017, a Instrução Normativa do ICMBio $\mathrm{n}^{\circ} 07$ deu novas diretrizes e procedimentos para a elaboração e revisão dos Planos de Manejo. Como relatado por alguns gestores entrevistados, essa IN foi resultado de uma parceria técnica entre ICMBio e o serviço de Parques Norte-Americano, que buscou adaptar uma metodologia mais simplificada de elaboração dos Planos de Manejo de todas as UCs, independente da categoria. Para o caso das Reservas Extrativistas, Reservas de Desenvolvimento Sustentável e outras Unidades de Uso Sustentável com populações tradicionais, no entanto, a IN ressalta algumas particularidades no seu capítulo IV, como a necessidade de se instituir um Grupo de Governança, com responsabilidades relacionadas ao processo de planejamento, a participação social, a estratégia de comunicação, pela interlocução com o conselho da UC e acompanhamento do processo de elaboração ou revisão do Plano de Manejo. Esse grupo deve ser formado pela equipe de planejamento do ICMBio, representantes das populações tradicionais, do conselho da UC e por assessores técnicos externos quando necessário. Diversos apontamentos constam na norma no sentido de promover a garantia de jure da participação, autonomia e valorização dos saberes das populações tradicionais.

Viana \& Sales (2008) também adicionam questões que tangenciam o entendimento do significado e função dos Planos de Manejo. Uma posição institucional clara sobre o papel do Plano de Manejo para o contexto das Resex é fundamental, já que, sendo ele definido como o principal instrumento de gestão de qualquer UC a partir da publicação do SNUC, não há como ignorar o conhecimento tradicional das populações beneficiárias, em benefício de um conhecimento técnico e externo à realidade local. Para além da simples "meta" ou cumprimento do protocolo legal, é fundamental a real utilidade desse instrumento (Kinouchi, 2015).

\section{Acordo de Gestão}

Após IN do ICMBio $\mathrm{n}^{\mathrm{0}}$ 29, de 2012, houve a institucionalização do Acordo de Gestão ${ }^{9}$, um instrumento que contém as regras construídas e definidas pela população tradicional beneficiária e o órgão ambiental, quanto às atividades tradicionalmente praticadas, o manejo dos recursos naturais, o uso e ocupação da área e a conservação ambiental. Podemos dizer que, com a IN n ${ }^{\circ} 29 / 2012$, a antiga proposta do Plano de Utilização foi substituída pelo Acordo de Gestão. Tal norma estabeleceu novas diretrizes para a construção deste documento, mas manteve seus objetivos centrados no ordenamento territorial, nas atividades extrativistas, agropastoris,

\footnotetext{
${ }^{9}$ A partir da publicação da IN n 7 de 2017, a IN que orientava os Acordos de Gestão passa a ser revogada, sendo estabelecido que "eventual Plano de Utilização ou Acordo de Gestão em vigor será incorporado ao plano de manejo". Ainda assim, esse instrumento será descrito neste artigo, pois ainda é utilizado em muitas Reservas Extrativistas.
} 
de pesca e outras atividades produtivas, além de disposições gerais e sobre monitoramento.

Segundo Brusnello (2015), havia uma demanda pelo aprimoramento dos Planos de Utilização, já que o instrumento "não foi sustentado durante a elaboração do SNUC, que não faz qualquer menção ao mesmo, reduzindo sua importância para a gestão e reforçando a prioridade dos Planos de Manejo" (p. 42). Como os planos de manejo também não vinham sendo implementados, como já discutimos anteriormente, houve a necessidade de recuperar um instrumento de cunho mais prático.

Das 21 Resex analisadas, 10 já elaboraram seu Acordo de Gestão, embora esse ainda não tenha sido publicado, pois aguardava uma resposta da Coordenação responsável em Brasília e/ou da Procuradoria Especializada do ICMBio para análise jurídica. Em algumas entrevistas os gestores demonstraram que também não há consenso se os Acordos de Gestão devem ser publicados separadamente, via Portaria no Diário Oficial da União, ou se devem aguardar e ser publicados como um capítulo do Plano de Manejo da reserva para ter ainda mais robustez normativa. A falta de amparo normativo parece ser determinante para os gestores nos momentos de fiscalização (ainda que os mesmos em unanimidade considerem esses momentos escassos).

\section{Acordo de Pesca}

Os acordos de Pesca também se mostraram presentes como instrumentos de ordenamento sobre os usos do território nas Resex Costeiras e Marinhas. Ainda que em menor grau do que os Planos de Manejo e os Acordos de Gestão, 4 Resex mencionaram possuir Acordos de Pesca vigentes.
Segundo Brusnello (2015), nos anos subsequentes ao SNUC ocorreu uma paralização na publicação dos Planos de Utilização e dos próprios Planos de Manejo. Na ausência de instrumentos que regulassem o uso dos recursos, o IBAMA publicou a IN n ${ }^{\circ}$ 29/2002, reconhecendo os Acordos de Pesca como instrumentos de ordenamento pesqueiro e estabelecendo critérios para a regulamentação dos mesmos.

O Acordo de Pesca é um conjunto de medidas específicas decorrentes de tratados consensuais entre os diversos usuários e o órgão gestor dos recursos pesqueiros, em uma determinada área definida geograficamente (IN no 29/2002). O processo de elaboração do Acordo também pressupõe a participação ativa dos usuários, por meio de mobilização, reuniões comunitárias e assembleias intercomunitárias.

Parte do sucesso de implementação desses acordos também está vinculada aos ajustes periódicos nas regras, de acordo com parâmetros definidos no monitoramento, assim como às ações de fiscalização (Ruffino, 2005). Os aspectos de monitoramento e de fiscalização emergiram das entrevistas como pontos problemáticos para o trabalho de gestão, especialmente por restrições orçamentárias e de recursos humanos.

\subsubsection{Instrumentos que se configuram como arenas de discussão e deliberação}

\section{Os Conselhos Deliberativos}

Outro instrumento que entra no cenário da cogestão a partir do SNUC são os Conselhos Deliberativos. Tais Conselhos são presididos pelo ICMBio, e constituídos por representantes de órgãos públicos, 
de organizações da sociedade civil e das populações tradicionais residentes na área (SNUC, 2000). Até novembro de 2016, todas as Resex analisadas possuíam Conselho Deliberativo ${ }^{10}$.

Pelo fato de serem deliberativos, os Conselhos de Resex estão aptos a tomar decisões sobre assuntos relacionados à gestão, emitem manifestações e resoluções, sendo que sua composição deve necessariamente garantir a maioria de representantes das populações tradicionais da Unidade. Ao se referir aos Conselhos, Viana \& Sales (2008) os identificam como o dispositivo legal que representa uma das mais significativas mudanças na legislação original das Reservas Extrativistas "na medida em que transfere a um conselho pluralista a responsabilidade pela gestão da unidade, anteriormente a cargo apenas das organizações que representavam os moradores e do órgão administrativamente responsável pela reserva" (p. 23). Para Cunha \& Loureiro (2009), há divergências de entendimento do significado da inserção do Conselho Deliberativo na cogestão das Resex, podendo haver diluição do poder dos comunitários que passam a dividir o poder decisório com outros entes.

É importante reconhecermos que, no detalhamento das normas publicadas sobre os Conselhos Gestores após o SNUC ${ }^{11}$, os mecanismos de participação e representação foram sendo reforçados (Prado et al., 2015). Ainda assim, a questão da representatividade foi mencionada como falha por diversos gestores entrevistados ao avaliarem a atuação dos conselheiros e a capilaridade entre Conselho e população local. Outro ponto mencionado foi o papel do ICMBio na presidência dos Conselhos. Esse aspecto diz respeito diretamente à tutela hierárquica do Instituto regulamentada pelos instrumentos jurídicos. Se, por um lado, tais procedimentos podem assegurar que os gestores das Resex sigam as normas e garantam os quesitos de representatividade, por outro lado, pode fazer com que os interesses do órgão ambiental se sobreponham aos interesses do Conselho de forma unilateral (Prado et al., 2015).

\section{Polos, Comitês de Gestão ou Comitês Comunitários}

Além dos Conselhos, foram observadas em algumas Resex outras instâncias de participação e organização comunitária, como os Polos e Comitês de Gestão ou Comitês Comunitários. Segundo um dos gestores entrevistados e que acompanhou a implementação de várias Resex, essa iniciativa surgiu especificamente no Estado do Pará, pelo grande número de comunidades inseridas no território da mesma unidade.

Cada polo representa a junção de um número de comunidades, geralmente agrupadas por proximidade geográfica. Cada polo tem uma cadeira no Conselho Deliberativo, e o representante de cada

\footnotetext{
${ }^{10} \mathrm{O}$ tempo médio para a criação dos Conselhos após a criação da UC variou de 2 a 19 anos. As duas primeiras Resex marinhas criadas, Resex Pirajubaé (1992) e Resex Arraial do Cabo (1997) tiveram um tempo mais longo, de 19 e 12 anos respectivamente, que se justifica pelo fato da regulamentação do conselho surgir somente após o SNUC (2000). Considerando apenas as Reservas criadas a partir dos anos 2000, o tempo médio para a criação do Conselho foi de aproximadamente 5 anos. Após criação, os conselhos devem ser renovados a cada dois anos. Além disso, a frequência das reuniões de cada Conselho é estabelecida em seu Regimento Interno e variou, segundo o levantamento, desde reuniões bianuais até a reuniões mensais.

${ }^{11}$ As normas regulamentadoras dos Conselhos de Resex para além do SNUC e decreto regulamentador de 2002 são IN nº 02 do ICMBio de 2007 - revogada e substituída pela IN nº 09 do ICMBio de 2014 em vigência.
} 
polo (conselheiro) responde por tais comunidades, que estão organizadas, por sua vez, em Comitês de Gestão ou Comitês Comunitários. Em alguns momentos esses comitês são referenciados como "Comitês de apoio ao Conselho Deliberativo", (Santos \& Schmitz, 2016), sendo constituídos por lideranças locais que vão auxiliar os representantes dos polos diretamente nas comunidades.

Esse canal, ainda que com algumas diferenças de funcionamento entre as Resex, acabou sendo regulamentado pela IN do ICMBIO ${ }^{\circ} 09$ de 2014, que prevê em seu artigo $5^{\circ}$ a atribuição do Conselho Deliberativo para "criar, se pertinente, o Comitê de Gestão, vinculado ao Conselho, que será composto pelo Instituto Chico Mendes e por representantes das populações tradicionais, o qual terá a atribuição de participar de forma colaborativa da gestão da Unidade de Conservação" (ICMBio, 2014). Há a necessidade de um maior aprofundamento sobre o funcionamento prático desses arranjos, mas potencialmente, há uma ampliação dos canais de diálogo e a diminuição das "distâncias da representatividade".

\subsubsection{Programas e Políticas Públicas institucionalizadas em Resex}

\section{Bolsa Verde}

O Programa Bolsa Verde foi criado pelo Governo Federal por meio da Lei no 12.512 de 2011.
Trata-se de um programa de transferência de renda com condicionalidades socioambientais ${ }^{12}$, que integrava o Plano Brasil sem Miséria e era destinado especificamente a povos e comunidades tradicionais como reconhecimento do papel desses grupos sociais para a conservação da natureza (MMA, 2011).

O Programa concede $\mathrm{R} \$ 300$ reais a cada três meses para as famílias beneficiárias e, de acordo com as informações do MMA (dados atualizados em 31/05/2017), 12.788 famílias eram beneficiárias do Programa Bolsa Verde nas Resex Costeiras e Marinhas. Em geral, os gestores entrevistados revelaram uma alta demanda de trabalho no atendimento às famílias beneficiárias do Bolsa Verde ${ }^{13}$. Por outro lado, também foi pontuada a relevância do Programa na mobilização das comunidades, quando pela primeira vez muitas famílias passaram a conhecer a Resex, entender seus objetivos e ampliar seu engajamento nas atividades de gestão.

É inegável que o programa também teve um impacto socioeconômico relevante, especialmente na visibilidade dos extrativistas pelo poder público. Em 2017, o Programa Bolsa Verde teve um corte de orçamento e em 2018 não apareceu na previsão orçamentária do MMA (SIGA, 2018).

\section{Créditos da reforma agrária}

Quando criadas, as Resex se tornam parte do Programa Nacional de Reforma Agrária do INCRA, que inclui créditos de instalação e fomento

\footnotetext{
${ }^{12}$ Dentre as condicionantes sociais, as famílias devem estar no Cadastro Único para Programas Sociais, do atual Ministério do Desenvolvimento Social e Agrário; estar dentro do perfil de renda definido pelo Bolsa Verde (famílias com renda de até R\$ 77 reais mensais por pessoa) e receber o Bolsa Família.

${ }^{13}$ Os gestores eram responsáveis por coletar as assinaturas das famílias nos termos de adesão ao programa e encaminhá-las ao MMA. Também deviam prestar informações e esclarecimentos sobre o Bolsa Verde e atuar no monitoramento ambiental, podendo ainda, auxiliar os municípios na localização das famílias em condição de extrema pobreza (Apoloni et al., 2014).
} 
TABELA 2 - Instrumentos de cogestão vigentes no desenho institucional das Resex Costeiras e Marinhas do Brasil, seus objetivos e estágio de implementação até novembro de 2016.

\begin{tabular}{lll}
\hline Instrumentos de Cogestão & Objetivos \\
\hline $\begin{array}{l}\text { Reconhecimento } \\
\text { territorial e de } \\
\text { beneficiários do } \\
\text { território }\end{array}$ & $\begin{array}{l}\text { Concessão de Direito } \\
\text { real de uso }\end{array}$ & $\begin{array}{l}\text { Concede à uma associação local, o direito de uso do território } \\
\text { da Resex por um período de 20 anos, sujeito ao cumprimento } \\
\text { de diversas condicionantes }\end{array}$ \\
\cline { 2 - 3 } & $\begin{array}{l}\text { Perfil da Familia } \\
\text { Beneficiária }\end{array}$ & $\begin{array}{l}\text { Documento que define, de forma participativa, os critérios } \\
\text { para as famílias beneficiárias das Resex }\end{array}$ \\
\hline
\end{tabular}

Estágio de implementação $(\mathbf{n}=\mathbf{2 1})$

Publicados $(n=15)$

Em andamento $(n=6)$

Publicados $(n=16)$

Concluídos, mas não publicados $(\mathrm{n}=5)$

Publicados $(n=3)$

Plano de Manejo Documento técnico contendo o zoneamento, descrição biofísica e as regras de uso e gestão dos recursos naturais

Iniciado e interrompido $(\mathrm{n}=8)$

Não iniciados $(\mathrm{n}=10)$

Publicados $(\mathrm{n}=1)$

Ordenamento sobre os usos do território

Acordo de Gestão

Regras definidas de forma colaborativa sobre o uso, práticas de gestão e ocupação do solo em linguagem e conteúdo menos complexos que o Plano de Manejo (não obrigatório)

Regras definidas de forma colaborativa sobre a pesca,

Acordo de pesca levando em consideração os interesses dos Pescadores e pescadores (não obrigatório)

Espaço institucionalizado, composto por representantes da sociedade civil, órgãos públicos e populações tradicionais, que negociam e deliberam sobre o uso e acesso dos recursos naturais
Em andamento $(\mathrm{n}=3)$

Não iniciados $(n=4)$

Concluídos, mas não publicados $(n=13)$

Publicados $(n=4)$

Concluído, mas não publicado $(n=1)$

Todas as Resex analisadas com Conselho implementado

Instância de participação e organização comunitária, com representantes locais dos interesses das comunidades, no

Existentes nos estados do

Polos e Comitês conselho deliberativo ou não. Ocorre especialmente em ca-

Comunitários sos onde há um número elevado de comunidades por Resex

Pará e Bahia

Programa de incentivo econômico de $\mathrm{R} \$ 300$ reais a cada 3 meses, para famílias em situação de extrema pobreza com condicionantes ambientais para conservação

Total de 12.788 famílias beneficiárias (em 31/05/2017)

\section{Programas e Políticas} públicas

Bolsa Verde

Incentivos econômicos na forma de créditos de instalação e fomento aplicados à produção e pertencentes ao Programa Não quantificado Nacional da Reforma Agrária - INCRA 
às famílias beneficiárias. Os créditos de instalação envolvem a construção de moradias; já os créditos de fomento

(no valor de até dois projetos de no máximo R\$ 3.200 reais cada) devem ser aplicados à produção (como petrechos de pesca e embarcações). É importante mencionar que, para muitas comunidades, os créditos do INCRA - como são comumente referenciados - representam a primeira chegada concreta de políticas públicas, especialmente em territórios isolados e com famílias vivendo em condições de renda precárias.

Não foi possível acessar os dados quantitativos sobre os recursos empregados em cada Resex Marinha. A sobreposição das autarquias INCRA-ICMBio foi relatada por alguns gestores como empecilho na implementação da política pública. Problemas de corrupção e injustiças locais sobre a distribuição dos recursos também foram mencionados, em geral, por conta de famílias que receberam crédito e não têm nenhuma relação com a pesca.

\subsection{O legado institucional das Resex: avanços e paradoxos}

A partir da análise da evolução dos arranjos formais nas Resex e seu panorama atual, observamos uma maior institucionalização dos processos de cogestão. $\mathrm{O}$ arcabouço apresentado nos resultados mostra robustez e dimensões de governança fundamentais para o desenvolvimento inclusivo e compartilhado de áreas protegidas.

No decorrer dessa trajetória, alguns instrumentos são retirados e retomam o arcabouço institucional antes e depois do SNUC, como é o caso dos Planos de Utilização, que se tornaram mais semelhantes aos Acordos de Gestão, e dos Planos de
Desenvolvimento, que, com algumas diferenças, se assemelhavam mais ao que representaram os Planos de Manejo. De cunho prático versus técnico, ou com base no conhecimento tradicional versus científico, esses instrumentos ainda refletem a dicotomia entre as visões socioambientalista e preservacionista enraizadas há décadas no debate sobre áreas protegidas (Diegues, 1996; Arruda, 1999; Santili, 2005).

A institucionalização da cogestão representada por seu desenho institucional desperta paradoxos interessantes. As entrevistas revelaram diversos entraves na implementação dos arranjos formais (Prado et al., in prep.), estruturados em uma lógica de funcionamento que ainda é hierárquica dentro do ICMBio e que se intensifica com as deficiências de orçamento e recursos humanos, aspectos levantados pelos gestores de forma unânime. A burocracia e a lógica tecnocrática do Estado levam a um engessamento procedimental e à morosidade da gestão, em detrimento de uma gestão que deveria ocorrer de forma dinâmica e adaptativa.

Cunha \& Loureiro (2012) apontam para uma ressignificação da noção de participação, levando-a para o âmbito moral, privado e individualista. "Com isso, os espaços públicos, anteriormente criados e necessários para o fortalecimento dos seringueiros como sujeitos revolucionários, são subsumidos [...] favorecendo a participação institucionalizada no interior dos aparelhos estatais sem destruir os marcos das relações capitalistas" (Cunha \& Loureiro, 2012, p. 57).

A busca pela igualdade, pela cidadania e por direitos sociais pode ter efeitos indesejados, que são acompanhados de um amplo processo de $j u$ ridificação das relações sociais (Nobre, 2004), ou por uma "progressiva ampliação dos domínios da vida regulados por normas legais" (op. cit, p. 27). 
Quando o Estado passa a ser um interlocutor direto nos territórios das Resex, ele assume a responsabilidade pela garantia de direitos e políticas públicas, estimulando a participação e não se limitando a uma relação Estado-cliente. Ao buscar concretizar uma relação Estado-cidadão, há sem dúvida um avanço institucional no âmbito da governança ambiental e no paradigma do Estado social de direito que deve ser ressaltado. Porém, paradoxalmente, corre-se o risco de que o modelo estatal oficial de participação sufoque, ou deixe de legitimar formas de participação já existentes e endógenas das comunidades, muitas vezes diminuindo, ainda que de forma controversa, o direito consuetudinário sobre esses territórios ${ }^{14}$.

Exemplos recorrentemente relatados pelos entrevistados são os entraves impostos pela Procuradoria Jurídica Especializada do ICMBio em face das tomadas de decisão dos Conselhos e da construção de acordos locais, especialmente a partir do momento em que estes passam a ser detalhadamente regulamentados. Isso é relatado com frequência no caso da elaboração dos critérios que compõem o perfil das famílias beneficiárias e das regras sobre o uso dos recursos estabelecidos nos acordos de gestão. Ainda não há um posicionamento institucional claro do ICMBio sobre temas polêmicos como a caça, a criação de animais de grande porte, o manejo do fogo e a utilização de petrechos de pesca proibidos nacionalmente sem considerar as peculiaridades regionais das Resex. Nesses casos, além da morosidade dos processos, as decisões unilaterais e muitas vezes distantes da realidade local são desafios para a gestão compartilhada.
Ainda assim, é imprescindível reiterar que, do ponto de vista institucional-legal, as Resex representam um modelo de governança inovador, que abarca dimensões inclusivas e cruciais para uma relação integrada entre sociedade e natureza. As dimensões a que nos referimos tratam do reconhecimento territorial e da regularização fundiária concedida a uma associação local; dos arranjos e possibilidades de ordenamento territorial e uso dos recursos construídos de forma democrática e participativa; dos espaços democráticos institucionalizados para o compartilhamento da tomada de decisões; e das políticas públicas voltadas para esses territórios.

Uma das grandes lacunas na elaboração e implementação das políticas para o público extrativista é a ausência de dados sobre sua população, suas condições sociais e econômicas (Apoloni et al., 2014). Esse fato reforça que os instrumentos de cogestão envolvendo um reconhecimento territorial e de beneficiários do território são fundamentais, aumentando a visibilidade desses povos para o Estado. Também é importante reconhecer essa robustez institucional como fruto de lutas políticas, dos movimentos sociais e de um esforço sistemático de setores socioambientais inseridos nos órgãos responsáveis (mais recentemente no ICMBio), influenciados por um modelo territorial de conservação e desenvolvimento inclusivos, concebido há mais de 30 anos pelo movimento seringueiro.

\section{Considerações finais}

${ }^{14}$ De modo geral, o direito consuetudinário é definido como um conjunto de normas sociais tradicionais, criadas espontaneamente pelo povo, não escritas e não codificadas. O verbete "consuetudinário" significa algo que é fundado nos costumes (Curi, 2012) 
Neste artigo objetivamos trazer a evolução e um panorama atual dos instrumentos de cogestão das Reservas Extrativistas, com recorte para as Resex da zona costeira. O arcabouço institucional das Resex contempla instrumentos de reconhecimento territorial e de beneficiários; instrumentos de ordenamento sobre os usos do território, arenas de discussão e deliberação, além de políticas públicas institucionalizadas em Resex.

O aprimoramento para a aplicação do desenho institucional pode caminhar para um maior reconhecimento e legitimidade das decisões locais, já que paradoxos foram observados especialmente quando as normas costumeiras deixam sua forma consuetudinária e se transformam, progressivamente, em direito codificado (Curi, 2012), e em um formato operativo de lógica tecnocrática.

A partir da compilação de informações e sistematização dos arranjos formais apresentados neste artigo, temos um grande desafio para as próximas décadas quanto ao desenho institucional que não apenas de jure, mas também de facto, represente um modelo de gestão genuinamente compartilhada em reservas extrativistas. Nesse caso, há que se avançar para que o exercício democrático de tais populações se concretize amplamente, e que todos os importantes instrumentos de cogestão construídos ao longo dos últimos 30 anos não se configurem como instrumentos de tutela, mas sim de emancipação social.

\section{Agradecimentos}

As autoras agradecem à FAPESP pelo Projeto de Auxílio à Pesquisa 2015/194398. D. Prado agradece à CAPES pela bolsa de estudos e em especial aos(às) analistas ambientais do ICMBio que gentilmente concederam entrevistas para esta pesquisa.

\section{Referências}

Allegretti, M. H. A construção social de políticas ambientais Chico Mendes e o Movimento dos Seringueiros. Tese (Doutorado em Desenvolvimento Sustentável). Universidade de Brasília. 2002.

Almeida, M. W. B. Direitos à Floresta e Ambientalismo: Seringueiros e suas lutas. Revista Brasileira de Ciências Sociais, 19(55), 2004.

Almeida, M. W. B.; Pantoja, M. C. Justiça local nas Reservas Extrativistas. Raizes, 23(1 e 2), 27-41, 2004.

Apoloni, R. C.; Nunes, J. F.; Gaivizzo, L. H. B.; Alves, S. A. Percurso de implementação de uma política socioambiental no Brasil: Programa de Apoio à Conservação Ambiental, Bolsa Verde. In: XIX Congreso Internacional del CLAD sobre la Reforma del Estado y de la Administración Pública, Quito. 2014.

Armitage, D.; Berkes, F.; Doubleday, N. Introduction: moving beyond co-Management. In: Armitage, D.; Berkes, F.; Doubleday, N. (Eds.). Adaptive co-management: collaboration, learning, and multi-level governance. UBC Press: Canada, 2007, p. 1-15.

Arruda, R. Populações Tradicionais e a proteção dos recursos naturais em unidades de conservação. Ambiente \& Sociedade, 5, 79-92, 1999.

Brusnello, L. D. Acordo de gestão de reserva extrativista: análise histórica e subsídios ao monitoramento. Dissertação (Mestrado Profissional em Biodiversidade em Unidades de Conservação). Instituto de Pesquisas Jardim Botânico do Rio de Janeiro. 2015.

Carlsson, L.; Berkes, F. Co-management: concepts and methodological implications. Journal of Environmental Management, 75, 65-76, 2005.

Cunha, L. H. O. Reservas Extrativistas: Uma alternativa de produção e conservação da biodiversidade. In: Encontro dos Povos do Vale do Ribeira, São Paulo. 2001. 
Cunha, C. C.; Loureiro, C. F. B. Reservas Extrativistas: limites e contradições de uma territorialidade seringueira. Revista Theomai, 20, 169-185, 2009.

Cunha, C. C.; Loureiro, C. F. B. Estado educador: uma nova pedagogia da hegemonia nas Reservas Extrativistas. Revista. Katálysis, 15(1), 52-61, 2012.

Curi, M. V. O Direito consuetudinário dos povos indígenas e o pluralismo jurídico. Espaço Ameríndio, 6(2), 230-247, 2012.

Chamy, P. Reservas Extrativistas Marinhas: um estudo sobre territorialidade marítima e Sustentabilidade. Dissertação (Mestrado em Ciências Ambientais). Universidade de São Paulo. 2005.

Diegues, A. C. O mito moderno da natureza intocada. São Paulo: Hucitec, 1996.

Faria, C. F.; Ribeiro, U. C. Desenho institucional: Variáveis relevantes e seus efeitos sobre processos participativos. In: Pires, R. R. C. (Org.). Efetividade das Instituições Participativas no Brasil: Estratégias de Avaliação. Diálogos para o Desenvolvimento. v.7. Instituto de Pesquisa Econômica Aplicada - Ipea, 2011.

Gomes, M. E. A. C.; Felippe, L. D. Tutela Jurídica sobre as Reservas Extrativistas. In: Anderson et al. (Eds.). O destino da floresta: Reservas extrativistas e desenvolvimento sustentável na Amazônia. Instituto de Estudos Amazônicos e Fundação Konrad Adenauer, 1994.

Jentoft, S. Co-management: The way forward. In: Wilson, D.C.; Nielsen, J. R.; Degnbol, P. The fisheries co-management Experience: Accomplishiments, Challenges and Prospects. Springer, 2003, p. 1-14.

Kinouchi, M. R. Plano de Manejo: Fundamentos para mudança. In: Bensusan, N.; Prates, A. P. A Diversidade cabe na Unidade? Áreas Protegidas no Brasil. IEB Mil Folhas, 2015, p. 221-249.

Medeiros, R. Evolução das Tipologias e Categorias de Áreas Protegidas No Brasil. Ambiente \& Sociedade, 9(1), 41-64, 2006.

Milano, Y. M. R. As implicações do Contrato de Concessão do Direito Real de Uso para Gestão de uma reserva extrativista Marinha. Revista de Direito dos Monitores da
$U F F, 11,2011$.

Murrieta, J. R.; Rueda, R. P. Reservas Extrativistas. UICN. 1995.

Nobre, M. Participação e Deliberação na Teoria Democrática: uma introdução. In: Coelho, V. S. P.; Nobre, M. Participação e Deliberação. Teoria Democrática e Experiências Institucionais no Brasil Contemporâneo. Editora 34, 2004, p. 21-41.

Prado, D. S.; Araujo, L.; Chamy, P.; Dias, A. C.; Seixas, C. $\mathrm{S}$. Conselhos Gestores de áreas protegidas no Brasil: reflexões sobre a participação social, desafios e possibilidades. Anais do VII Seminário Brasileiro sobre Áreas Protegidas e Inclusão Social - SAPIS e II Encontro Latino Americano sobre Áreas Protegidas e Inclusão Social-ELAPIS. UFSC. Florianópolis, 2015, p. 25-34.

Prado, D. S.; Castro, F.; Seixas, C. S. Institutional and legal framework of Marine Extractive Reserves: Gaps between State Structure and the dramas of implementation. In prep.

Porto Gonçalves, C. W. A Territorialidade Seringueira. Geografia e Movimento social. GEOgraphia, 2, 1999.

Ruffino, M. L. Gestão do Uso dos Recursos Pesqueiros na Amazônia. Manaus: IBAMA. 120p. 2005.

Santilli, J. Socioambientalismo e novos direitos: Proteção jurídica à diversidade biológica e cultural. Editora Peirópolis, Instituto Socioambiental e Instituto Internacional de Educação do Brasil, 2005.

Santos, L. C. B.; Schmitz, H. As dificuldades da participação dos usuários na gestão da reserva extrativista marinha de Maracanã, estado do Pará. Enciclopédia biosfera, 13(23), 2016.

SIGA BRASIL. Painel Cidadão. Senado Federal. 2018. Disponível em http://www9.senado.gov.br/QvAJAXZfc/ opendoc.htm?document=senado $\% 2$ Fsigabrasilpainelcidadao.qvw\&host $=$ QVS $\% 40 \mathrm{www} 9 \&$ anonymous $=$ true $\&$ Shee$\mathrm{t}=$ shOrcamentoVisaoGeral. Acesso em 07/03/18.

Vianna, L. P.; Sales, R. R. Análises e diretrizes para consolidação da Categoria reserva extrativista. Relatório final. Brasília. 2008. 